\title{
Article
}

\section{Kinesio Taping reduces pain and improves disability in Low Back Pain patients: a randomised controlled trial}

Macedo, LB, Richards, James, Borges, DT, Melo, SA and Brasileiro, JS

Available at http://clok.uclan.ac.uk/23667/

Macedo, LB, Richards, James ORCID: 0000-0002-4004-3115, Borges, DT, Melo, SA and Brasileiro, JS (2019) Kinesio Taping reduces pain and improves disability in Low Back Pain patients: a randomised controlled trial.

Physiotherapy, 105 (1). pp. 65-75. ISSN 0031-9406

It is advisable to refer to the publisher's version if you intend to cite from the work. http://dx.doi.org/10.1016/j.physio.2018.07.005

For more information about UCLan's research in this area go to http://www.uclan.ac.uk/researchgroups/ and search for <name of research Group>.

For information about Research generally at UCLan please go to http://www.uclan.ac.uk/research/

All outputs in CLoK are protected by Intellectual Property Rights law, including Copyright law. Copyright, IPR and Moral Rights for the works on this site are retained by the individual authors and/or other copyright owners. Terms and conditions for use of this material are defined in the policies page.

\section{CLoK}

Central Lancashire online Knowledge www.clok.uclan.ac.uk

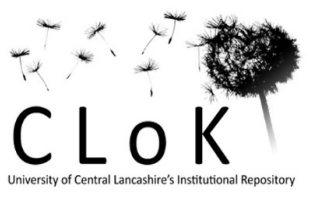


1 Kinesio Taping reduces pain and improves disability in Low Back Pain patients: a randomised controlled trial.

3 Macedo LB, Richards J, Borges DT, Melo SA, Brasileiro JS.

4

\section{Abstract}

Objectives: Investigate the effects of Kinesio Taping® ${ }^{\circledR}(\mathrm{KT})$ on chronic nonspecific low back pain (LBP) Design: Randomised controlled trial with intention-to-treat analysis. Setting: University laboratory. Participants: One hundred eight women with chronic nonspecific LBP underwent an evaluation pre, three and ten days after intervention. Interventions: After randomization, participants were assigned in four groups: KT with tension group (KTT) applied Kinesio Taping ${ }^{\circledR}$ with tension in the region of the erector spinae muscles; KT no tension group (KTNT) applied Kinesio Taping ${ }^{\circledR}$ with no tension at the same region; Micropore ${ }^{\circledR}$ group (MP) applied Micropore ${ }^{\circledR}$ tape on the erector spinae muscles; and Control group (CG) did not receive any intervention. Main outcome measures: The primary outcome was pain sensation, measured by numerical pain rating scale. Secondary outcomes were: disability, trunk range of motion, strength and electromyographic amplitude, measured by Roland Morris Disability questionnaire, inclinometry, dynamometry and electromyography, respectively. Results: Pain relief was observed for KTT group (mean difference=1,963; CI 95\%=0,501 - 3,425; p=0,003) and KTNT group (mean diference=1,926; CI $95 \%=0,464-3,388 ; p=0,004)$ compared to control group at 3 days after application of the tape. For disability there was difference between control group and KTT group at 3 (mean difference=3,481; CI 95\%=0,825 - 6,138; p=0,004) and 10 days (mean difference=3,185; CI 95\%=0,395 - 5,975; p=0,016). For all the others variables, there was no differences between group. Conclusion: KT with or without tension reduces pain 3 days after its application. Additionally, when applied with tension it improves disability after 3 and 10 days in LBP patients.

Trial registration: NCT02550457 (clinicaltrials.gov). 
8

9

0

1

2

3

- Kinesio Taping reduces pain and disability in patients with chronic nonspecific low back pain;

- There is no difference between the use of Kinesio Taping with or without tension for pain;

- The Micropore group showed no differences compared to either Kinesio Tape or Control groups.

- No alterations on physical measures were observed.

Key words: Spine; back muscles; bandage; electromyography. 


\section{Introduction}

The high incidence of Low Back Pain (LBP) is burdensome in the world population and causes more disability than any other condition [1]. It is associated with psychological, social and biophysical factors that impair function, social participation, job satisfaction and socioeconomic status [2]. Numerous treatments for LBP have been studied [1,3], and recently the use of Kinesio Taping (KT) has become a popular treatment option for many conditions, including LBP [4].

Kinesio Taping was developed in 1973 by the Japanese chiropractor Kenzo Kase [5]. This technique uses an extremely thin functional elastic bandage, with an approximate thickness of the epidermis. It can be longitudinally extended up to 120$140 \%$ of its original length, having similar elasticity to the skin [6,7]. KT has been reported to be able to increase blood and lymph circulation, improve muscle performance, reduce pain, realign joints, reduce muscle tension $[7,8,9]$ and change motor unit recruitment [10]. However, the mechanism by which KT achieves this is not clear. It has been suggested that its application to the skin activates cutaneous mechanoreceptors, which results in pain relief through the pain gate theory [10]. Furthermore, it has been reported to provide an increase of the interstitial space, permitting improved blood and lymph flow due to its elastic and adhesive characteristics $[7,9]$. Regarding the hypothesis of increased muscle activity, this could be due to neurofacilitation, with a suggested mechanism that the tactile stimulation provided by the bandage activates cutaneous receptors provoking stimulation of alpha 
motoneurons [11,12]. However, detailed studies relating to the efficacy and effectiveness of KT are still limited and controversial.

Recent studies on LBP have shown an improvement in pain $[8,10]$, disability [8], Range of Motion (ROM) of lower trunk [13] and lumbar muscles activation [10] in subjects who underwent treatment with KT, while others have shown no such differences with the application of KT or placebo taping [14,15]. For example several authors analysed pain and disability and shown good results related to these variables in patients using tape $[8,10,16,17,18]$, however other authors have shown no superiority of its effects compared to placebo treatments $[14,19,20,21]$, or similar or slightly superior effects [22,23].

There are few studies that have analysed the effect of KT on ROM and electromyography (EMG) [12,13]. Despite EMG being suggested as a useful tool in the assessment of muscle dysfunction associated with LBP [24], little work has been published identifying changes due to taping, with the majority of studies being conducted using healthy subjects [25,26] or lower limb injuries [27]. Patients with LBP have been show to demonstrate different EMG patterns compared with healthy subjects $[28,29]$, however variations EMG between static to dynamic tasks have been observed due to high tension or inhibitory mechanism of pain, and demonstrate greater asymmetry in muscle activation and higher fatigability [24], making the comparison of studies difficult.

Considering the lack of consensus in the literature and the increasing use of KT, it is pertinent to question the effects of Kinesio Taping ${ }^{\circledR}$ in individuals with LBP. Thus, 
this study aims to evaluate the isolated effect of KT on pain, disability, range of motion, strength and muscle activity in individuals with chronic nonspecific LBP.

\section{Method}

\section{Design}

This was an assessor blinded prospective randomised controlled trial. The study was conducted at the University Laboratory of X.

\section{Ethics}

This study was approved by the Research Ethics Committee of the local University under the protocol number 1.213.864, registered on the clinicaltrials.gov website (NCT02550457) and it is in accordance with CONSORT recommendations. All volunteers were informed about the objectives of the study and signed the consent form.

\section{Subjects}

One hundred eight female with a mean age of 25 (5) years and a mean Body Mass Index (BMI) of $22.8(2.9) \mathrm{kg} / \mathrm{m}^{2}$, were recruited to the study from the community, orthopedics and rheumatology clinics, Pilates and fitness centers through verbal and printed advertising. Inclusion criteria were: age between 18 and 50 years old and having chronic nonspecific LBP for more than 3 months. Exclusion criteria: diagnosis of fractures or tumours in the spine, ankylosing spondylitis, disc herniation, spondylolisthesis with neurological involvement, lumbar stenosis, previous spinal 
surgery, fibromyalgia and any central or peripheral neurological diseases. Volunteers were also excluded from the study if they were pregnant, were on their menstrual cycle or the premenstrual period, had a BMI over 30, had a NPRS less than 2 in the last 24 hours of the first evaluation, or if they had used corticosteroids in the last two weeks or any anti-inflammatory medication in the last 24 hours. They were also excluded if they presented signs of allergy/intolerance to the KT during a test conducted before the initial evaluation or had undergone prior treatment with this technique in the lumbar region. Furthermore, volunteers were excluded if they demonstrated a lack of understanding of the instructions in the proposed protocol and/or inadequate performance of the evaluations.

\section{Procedure}

Block randomisation was performed by a researcher independent, and the order of the participants were numbered and sealed in opaque envelopes. Participants were allocated in four different groups: control group (CG), KT with tension group (KTT), KT no tension group (KTNT) and Micropore® group (MP). Separate researchers performed the assessment (researcher 1), intervention (researcher 2) and data analysis (researcher 3) to minimise potential sources of bias. The initial assessment was carried out and data recorded before the envelopes were opened.

Due to the presence of a group without tape, it was not possible for the participants and researchers 1 and 2 to be blinded to the treatment. However, before any analysis was performed the data were coded by researcher 2, so that the statistical analysis performed by researcher 3 was blinded. 


\section{Intervention}

The KTT group received application of Kinesio Taping that was positioned in the form of "I" over the erector spinae muscles bilaterally [14]. The tape was applied with the participants seated, with the spine in anatomical position for the application of the anchor, which was positioned in the sacral region (S1) without tension [30]. The participants were then asked to perform trunk flexion and rotation to the opposite side to the application of the tape with a slight stretch of approximately $10-15 \%$, which was then repeated on the opposite side [30]. The tape was fixed with tension from the posterior superior iliac spine to the T12 with a final anchor point fixed directly above the T12 with $0 \%$ of tension [30] (Figure 1 - A).

For the participants in the KTNT group, KT was applied in a similar way as the previous group, except they were asked to hold a neutral pose and no tension was applied to the tape (Figure 1 - B). Finally, to the participants in the Micropore ${ }^{\circledR}$ group, the application was performed in the same way as the KTT group. The participants of the control group did not receive any intervention.

\section{Insert Figure 1}

Participants in the experimental groups were instructed to leave the tape applied to the area for three days until re-evaluation, the time usually recommended in clinical practice and in accordance with Kase et al. [7], after which the KT can start to become detached from the skin.

\section{Outcome measures}


151 On completion of the tests during the re-evaluation on 3 days, the tape was removed

152 and the participant was asked to return to the laboratory a week later for the final 153 evaluation, 10 days after the first assessment, which was performed at the same day of 154 the week and time as second evaluation.

Assessment comprised of pain intensity, disability, trunk range of motion, strength and electromyographic amplitude. The assessment of pain intensity was the primary outcome evaluated using a numerical pain rating scale across a range of 11 , with 0 being described as "no pain" and 10 as "worst possible pain". Participants were instructed to report the level of pain intensity based on the last 24 hours [30].

\section{Functional status was assessed using the Roland Morris Disability}

Questionnaire which provides a score on 24 items that describes daily tasks, where 0 represents no disability and 24 represents serious disabilities. Participants were instructed to fill the items that actually apply to them over the last 24 hours [30].

In addition, the trunk range of motion was assessed using an iPhone ${ }^{\circledR}\left(\mathrm{iPhone}{ }^{\circledR}\right.$ model 6, Apple Inc., California) application iHandy level ${ }^{\circledR}$, which was first calibrated on a level surface and worked as a gravity inclinometer. This application has previously been found to be reliable and has been validated by several studies [31,32]. This was used to measure the movements of flexion, extension, lateral flexion to the left and right of the spine, according to the guideline established by Wanddell et al [33]. 
171 in contact with the skin of the participant, while the central region of this edge was

172 placed at the level of T12-L1 (Figure 2). The participants were asked to flex their trunk

173 moving until the limit of their ROM and hold the position while the angle was recorded.

174 The same procedure was performed for extension, however, for this movement, 175 participants were asked to support their hands on the lower back at the L4-L5 to 176 facilitate their balance [31]. For lateral flexion the device was positioned horizontally 177 parallel to the ground with the display directed to the investigator on the level of T9178 T12 (Figure 2). Participants were asked to slide their hand down the side of the leg as 179 far as possible while maintaining trunk and head facing forward whilst keeping both 180 feet on the ground, first moving to the right and then to the left. To ensure the reliability 181 of test-retest, the position and orientation of the iPhone was marked out with a 182 dermographic pen using the spinous processes as a reference. Each movement task was 183 repeated twice with 30-second interval between trials and a familiarization was allowed 184 before trials. The repetition with greater amplitude was used in the analysis.

An EMG assessment was performed using a Telemyo direct transmission system and 8 channels wirelessly system (Noraxon ${ }^{\circledR}$, USA) with 16-bit resolution and 188 common mode rejection $(\mathrm{CMR})>100 \mathrm{db}$. Signals were captured with a sampling 189 frequency of $1500 \mathrm{~Hz}$, amplified 1000 times and filtered with a bandpass of $10-500$ 190 Hz. The signals were captured using passive self-adhesive surface electrodes (4 x 2.2 191 $\mathrm{cm}$ ) in a bipolar arrangement, with an inter-electrode distance of $2 \mathrm{~cm}$. Before attaching 
the electrodes, participant's skin was shaved and cleaned with alcohol 70\%. The electrodes were placed bilaterally in the longissimus muscles, in accordance with the SENIAM guidelines [34]. The analysis software used was the MyoResearch 3.8 (Noraxon®, USA).

A dynamometric evaluation of the trunk extensor strength was performed using a portable hand held dynamometer (Lafayette Instrument ${ }^{\circledR}$, model 01165, USA). Participants were positioned in prone on a plinth with their hands clasped behind their neck [35] and then guided to conduct trunk extension for two seconds for familiarization (Figure 3). After one-minute rest, two Maximum Voluntary Isometric Contraction (MVIC) were performed during 5 seconds each, with a two minutes interval. The dynamometer was positioned centrally between the two lower edges of the shoulder blades and fixed by a band. Two other bands were used to stabilize the participant, positioned above the popliteal line and above the lateral malleolus. During the two contractions the maximum extensor strength (in Newton) and the Root Mean Square (RMS) of the longissimus muscle were recorded. The electromyographic data (in microvolts) was normalized by the peak of the signal recorded during the MVIC, and strength was normalized to body weight $(\mathrm{kg})$ [35].

\section{Insert Figure 3}

\section{Statistical Analysis}

A sample size of 108 participants, 27 in each group, was identified as sufficient to detect a 2-point clinically significant difference [36] between groups in the pain intensity outcome, measured by the NPRS. This assumed a standard deviation of 2.5 
points, estimated from a previous pilot study, with a statistical power of $80 \%$, alpha of $5 \%$ and a loss rate of $10 \%$ [37].

All statistical analyses were conducted following the principles of intention to treat using the Statistical Package for the Social Science software (SPSS) version 20.0. A mixed methods ANOVA (4x3) was used to analyse the differences between the four groups (CG, KTT, KTNT, MP) over the three time points (Pre, 3 days, 10 days) and group/time interactions. In addition, the effect size was calculated using $\eta^{2}$ which reports the proportion of the total variance within the dependent variables. The

222 homogeneity of variance was verified by the Levene test. When the assumption of 223 sphericity was violated, significance was adjusted using Greenhouse-Geisser. When the effect of the test was significant, post hoc pairwise comparisons were performed using a Bonferroni adjustment for multiple comparisons with a 0.05 significance level.

\section{Results}

Flow of participants through the study

The design of the study is shown on Consort diagram (Figure 4). One hundred thirty-two volunteers were selected by inclusion. Twenty-four (18\%) were excluded

230 according the eligibility criteria, seven had a NPRS less than 2, one had history of

231 fracture on lumbar spine, one had spondylolisthesis with neurological involvement, one was submitted to a previous back surgery, one had utilized KT on lumbar region previously, two had a BMI>30, three were over 50 years, two were men and six declined to participate. In total 108 participants were included and randomly allocated 
to one of four groups: CG $n=27$, mean age 24 (4) years; KTT $n=27$, mean age 25 (6) years; KTNT n=27, mean age 24 (5) years; and MP n=27, mean age 25 (5) years. Ten data sets were lost in total (9\%), one of which was in the control group (withdrew), three in the KTT group (one volunteer abandoned the study and two where the tape fell off), two in the KTNT group (where tape fell off) and four in MP group (all due the tape falling off).

\section{Analysed variables}

The sample homogeneity between groups at baseline for age, body mass index, pain, disability, range of motion, RMS and strength are shown on Table 1 as mean (standard deviation).

\section{Insert Figure 4}

Insert Table 1

Table 2 shows the mean values (standard deviation) of all analysed variables, for the four groups, at the three time points of evaluation.

\section{Insert Table 2}

Mixed methods ANOVAs showed significant differences between groups for pain $\left(\mathrm{p}=0.036, \mathrm{np}^{2}=0.079\right)$ and disability $\left(\mathrm{p}=0.010, \mathrm{p}^{2}=0.102\right)$. Specifically, there was an improvement between KTT and KTNT groups compared to control group for NPRS three days after intervention. For disability, there was an improvement between KTT group and the control group at 3 and 10 days (Table 3). 
A significant interaction was seen between group and time $(\mathrm{p}=0.016)$ for pain. Further pairwise comparisons showed a mean difference of $2.4(\mathrm{p}<0.001)$ and 1.5 $(\mathrm{p}=0.011)$ in pain between pre intervention and 3 days and between pre intervention and 10 days, respectively, for the KTT group. For KTNT group, a mean difference of 2.4 between pre versus 3 days $(\mathrm{p}<0.001)$ and 1.7 between pre versus 10 days $(\mathrm{p}=0.003)$ was observed. For MP group, it was observed a mean difference of $1.3(\mathrm{p}=0.022)$ and $1.7(\mathrm{p}=0.003)$ between pre versus 3 days and between pre versus 10 days, respectively. These changes should be considered with respect to Ostelo et al. [36] who reported values over 2 points in NPRS to be a clinically important change.

The same effect was seen for disability with a significant interaction between group and time $(\mathrm{p}=0.018)$. Further pairwise comparisons showed an improvement between pre versus 3 days ( $\mathrm{p}<0.001$, mean difference of 3.2 ) and pre versus 10 days ( $<<0.001$, mean difference of 3.4) for the KTT group; pre versus 3 days ( $<<0.001$, mean difference of 2.9) and pre versus 10 days ( $\mathrm{p}=0.009$, mean difference of 1.9 ) for the KTNT group; and pre versus 3 days $(\mathrm{p}=0.005$, mean difference of 1.8$)$ and pre versus 10 days ( $\mathrm{p}=0.002$, mean difference of 2.3) for MP group. All the values between time points for KTT group and between pre versus 3 days for KTNT group showed more than $30 \%$ of improvement, which also could be considered as a clinically important change[36].

Mixed methods ANOVAs showed significant differences between time points; for extension $\left(\mathrm{p}<0.001, \mathrm{np}^{2}=0.090\right)$ a difference was seen between pre versus 3 days 
(Mean Difference of - 1.8) and pre versus 10 days (Mean Difference of - 2.8); for right lateral flexion $\left(\mathrm{p}=0.008, \mathrm{np}^{2}=0.045\right)$ there was difference between both pre versus 3 days (Mean Difference of - 0.9) and pre versus 10 days (Mean Difference of - 1.0); for right $\mathrm{RMS}\left(\mathrm{p}=0.001, \mathrm{np}^{2}=0.065\right.$ ) it was observed differences between pre versus 3 days (Mean Difference of - 4.9) and pre versus 10 days (Mean Difference of - 4.3); for left RMS ( $\mathrm{p}<0.001, \mathrm{np}^{2}=0.081$ ) a difference was observed for both pre versus 3 days (Mean Difference of - 5.1) and pre versus 10 days (Mean Difference of - 5.4); and for strength $\left(\mathrm{p}<0.001, \mathrm{np}^{2}=0.180\right)$ it was observed a difference for pre versus 3 days (Mean Difference of - 20) and pre versus 10 days (Mean Difference of -20). However, there was no significance difference between groups and no interaction between group and time.

\section{Discussion}

This study aimed to evaluate the effect of Kinesio Taping on individuals with nonspecific LBP using outcomes of pain, disability, range of motion, strength and electromyographic amplitude. To our knowledge, this is the first study to analyse these variables together with the view to compare the effect of different tape and the application of different techniques. The results showed reduced pain after three days in both KT groups (with and without tension), in addition disability showed an improvement at 3 and 10 days for KT with tension group only. All other statistical comparisons between groups did not show any statistical significance, indicating improvements only in the groups who underwent Kinesio Taping. 
299 after KT application [8,10]. Paoloni et al. [10] observed a pain relief shortly after tape 300 application and also after four weeks of intervention. They evaluated the effects of the 301 tape versus tape combined with exercise and only exercise, however they did not find 302 any significant differences between groups, although pain between time points showed 303 clinically important differences. The same was seen in our results, which showed 304 changes greater than those considered to be minimal clinically importance changes in pain [36] for KT with and without tension at 3 days of evaluation. Castro-Sanchez et al. [8] found a greater improvement of pain for the experimental group, which applied 307 KT over the lumbar spine, at seven days of treatment and four weeks after the intervention. Nevertheless, these findings did not pass the threshold of what can be considered clinically important.

Previous studies [14,38] found reductions in pain after treatment which reached the threshold for a clinically important change [36], however these authors did not support its use as no differences were seen between groups. Although, it is important to highlight that these studies did not use a control group without intervention.

Kelle et al. [18] and Luz Júnior et al. [20] analysed the effects of KT compared to a non-intervention group in LBP and both found a statistically significant difference 316 between the experimental and control group. However, the results of Luz Júnior et al. 317 [20] did not reach the threshold for a clinically important change. Moreover, they found 318 the same results to Micropore tape, arguing that this demonstrates a placebo effect. 319 However this current study did not find differences between control group and 
Micropore group, and no statistical difference between Micropore tape and Kinesio Taping was seen.

The potential mechanism by which KT reduces pain is beyond the scope of this study, however one hypothesis that has been suggested is the gate control theory of pain $[8,10,22]$, which suggests that the mechanical stimulus provided by the tape would act through the large-diameter non-nociceptive fibres resulting in pain inhibition and relief. The analgesia ceases, however, as soon as the stimulus is removed. This is in agreement with our results, which showed reduction of the pain at 3 days, while the tape was applied. However, due the lack of differences between Micropore group and the groups that applied KT, the hypothesis of placebo mechanism must also be considered.

In terms of disability, our results showed a clinically important improvement up to 10 days in the KT with tension group only. In contrast, Parreira et al. [14] despite observing an improvement of disability in tape with and without tension, showed no significances between groups. Other authors $[8,18,20,38]$ also observed significant improvement for disability, but with differing evaluation time points, varying between 48 hours to 5 weeks of intervention. None of the studies found showed improvement after a follow-up period without tape. However, the variation in these findings could be due the different protocols used.

Besides disability has a direct relationship with pain, its genesis in chronic conditions is generally multifactorial and may have a different clinical presentation [39]. It can be suggested that the tension provided by the tape can enhance the proprioceptive feedback and facilitate the posture and the correct movement, even after 
its withdrawal. Some authors $[40,41]$ agree that this improvement in proprioception may provide feedback to achieve and maintain preferred body alignment and give to the patients more awareness of the back while movements, hence reducing detrimental movements [8].

Edin et al. [42] suggested that joint motions are associated with a predictable patterns of changing strain in the surrounding skin. The application of the tape would therefore stimulate the skin and change the strain, stimulating cutaneous receptors and improving the movement control.

Although the tape provided improvements in pain and disability, no significant differences were seen between groups for ROM assessed by inclinometry in our study. An improvement was detected for extension and right lateral flexion between time, but without an interaction between group and time. Previous studies used clinical tests or instruments as fleximeters $[8,13,15,43,44]$ and analysed different movements in patient 355 populations, making interpreting difficult.

With regards to neuromuscular performance, literature shows that KT does not 357 alter neither strength nor electromyography [25,26,27,45]. Paoloni et al. [10] used EMG 358 to determine the effect of the tape on back pain. However, they analysed the flexion359 relaxation during trunk flexion, whereas our study also included extension and lateral 360 flexion. Our aim was to verify if the KT would improve the strength, increase 361 electromyographic amplitude and enhancing the strength through the stimulation 362 cutaneous receptors [46]. However, even though there was an increase of the RMS and 363 strength in relation to the time, there was no difference between groups or group and 
time, concluding that this technique is not able to improve the performance of back muscles.

Finally, it is suggest that $\mathrm{KT}$ is capable to reduce pain while applied, with or without tension, and improve disability, even after its withdrawal, when applied with tension. However, there was no effect on ROM, electromyography activity or strength. Although there were improvements observed in the subjective measures, but these showed no superiority of the results of KT compared to MP group, a potential placebo effect should be considered. It is important to note that these findings are limited to young women with chronic nonspecific low back pain and that the tape was applied only once with a short follow-up of ten days.

Ethical Approval: The Ethics Committee of X approved this study (protocol number 1.213.864).

Funding: This work was supported by X. 


\section{References}

399 [1] Hoy D, March L, Brooks P, Blyth F, Woolf A, Bain C et al. The global burden 400 of low back pain: estimates from the Global Burden Disease 2010 study. Ann $401 \quad$ Rheum Dis 2014; 73: 968-74. 
402

403

404

405

406

407

408

409

410

411

412

413

414

415

416

417

418

419

420

421

422

423

424

425

426

[2] Hartvigsen J, Hancock MJ, Kongsted A, Louw Q, Ferreira ML, Genevay S et al. What low back pain is and why we need to pay attention. Lancet 2018; published online March 21. http://dx.doi.org/10.1016/S0140-6736(18)30480-X.

[3] Foster NE, Anema JR, Cherkin D, Chou R, Cohen SP, Gross DP et al. Prevention and treatment of low back pain: evidence, challenges, and promising directions. Lancet 2018; published online March 21. http://dx.doi.org/10.1016/S0140- 6736(18)30489-6.

[4] Parreira PCS, Costa LCM, Hespanhol Junior LC, Lopes AD, Costa LOP. Current evidence do not support the use of Kinesio Taping in clinical practice: a systematic review. J Physiother 2014; 60: 31-9.

[5] Kase K, Lemos TV, Dias EM. Kinesio Taping: Introdução ao método e aplicações neuromusculares. 1st ed. São Paulo: Andreoli; 2013.

[6] Kase K, Tatsuyuki H, Tomoko O. Development of Kinesio tape. Kinesio Taping Perfect Manual. Kinesio Taping Association; 1996.

[7] Kase K, Wallis J, Kase T. Clinical therapeutic aplications of the kinesio taping method. 2nd ed. Kinesio Taping Association; 2003.

[8] Castro-Sánchez AM, Lara-Palomo IC, Matarán-Peñarrocha GA, FernándezSánchez M, Sánchez-Labraca N, Arroyo-Morales M. Kinesio Taping reduces disability and pain slightly in chronic non-specific low back pain: A randomised trial. J Physiother 2012;58(2):89-95.

[9] Thelen M, Dauber J, Stoneman P. The Clinical Efficacy of Kinesio Tape for Shoulder Pain: A Randomized, Double-Blinded, Clinical Trial. J Orthop Sport PhysTher 2008;38(7):389-95.

[10] Paoloni M, Bernetti A, Fratocchi G, Mangone M, Parrinello L, Cooper MDP et al. Kinesio Taping applied to lumbar muscles influences clinical and 

electromyographic characteristics in chronic low back pain patients. Eur J Phys Rehabil Med 2011;47(2):237-44.

[11] Halseth T, McChesney JW, DeBeliso M, Vaughn R, Lien J. The effects of Kinesio taping on proprioception at the ankle. J Sports Sci Med 2004; 3:1-7.

[12] Macgregor K, Gerlach S, Mellor R, Hodges PW. Cutaneous stimulation from patella tape causes a differential increase in vasti muscle activity in people with patellofemoral pain. J Orthop Res 2005; 23(2): 351-58.

[13] Yoshida A, Kahanov L. The effect of kinesio taping on lower trunk range of motions. Res Sports Med 2007;15(2):103-12.

[14] Parreira PCS, Costa LCM, Takahashi R, Hespanhol Junior LC, Luz Junior MA, Silva TM et al. Kinesio Taping to generate skin convolutions is not better than sham taping for people with chronic non-specific low back pain: A randomised trial. J Physiother 2014;60(2):90-6.

[15] Salvat IS, Salvat AS. Efectos inmediatos del kinesio taping en la flexión lumbar. Fisioterapia 2010;32(2):57-65.

[16] AlBahel F, Hafez AR, Zakaria AR, Al-AhaidebA, Buragadda S, Melam GR. Kinesio taping for the treatment of mechanical low back pain. World Appl Sci J 2013; 22: 78-84.

[17] Kaplan Ş, Alpayci M, Karaman E, Çetin O, Özkan Y, İlter S et al. Short-term effects of Kinesio taping in women with pregnancy-related low back pain: A randomized controlled clinical trial. Med Monit 2016; 22:1297-1301.

[18] Kelle B, Güzel R, Sakalli H. The effect of Kinesio taping application for acute non-specific low back pain: A randomized controlled clinical trial. Clin Rehab 2016; 30(10): 997-1003. 
[19] Parreira PCS, Costa LCM, Takahashi R, Hespanhol Junior LC, Luz Junior MA, Silva TM, et al. Kinesio Taping to generate skin convolutions is not better than sham taping for people with chronic non-specific low back pain: A randomised trial. J Physiother 2014;60(2):90-6.

\section{[20] Luz Júnior MA, Sousa MV, Neves LA, Cezar AA, Costa LO. Kinesio Taping®} is not better than placebo in reducing pain and disability in patients with chronic non-specific low back pain: a randomized controlled trial. Braz J Phys Ther 2015; 19(6): 482-90.

[21] Vanti C, Bertozzi L, Gardenghi I, Turoni F, Guccione AA, Pillastrini P. Effect of taping on spinal pain and disability: systematic review and meta-analysis of randomized trials. Phys Ther 2015; 95(4): 493 - 506.

[22] Artioli DP, Bertolini GRF. Kinesio taping: application and results on pain: systematic review. Phys Ther Res 2014; 21(1): 94-9.

[23] Lim ECW, Tay MGX. Kinesio taping in musculoskeletal pain and disability that lasts for more than 4 weeks: is it time to peel off the tape and throw it out with the sweat? A systematic review with meta-analysis focused on pain and also methods of tape application. Br J Sports Med 2015; 0:1-10.

[24] Alschuler KN, Neblett R, Wiggert E, Haig AJ, Geisser ME. Flexion-relaxation and clinical features associated with chronic low back pain: a comparison of different methods of quantifying flexion-relaxation. Clin J Pain 2009; 25(9): 76066.

[25] Lins CAA, Locks Neto FL, Amorim ABC, Macedo LB, Brasileiro JS. Kinesio Taping ${ }^{\circledR}$ does not alter neuromuscular performance of femoral quadriceps or lower limb function in healthy subjects: Randomized, blind, controlled, clinical trial. Man Ther 2013; 18(1): 41-5. 
[26] Lins CA, Borges DT, Macedo LB, Costa KS, Brasileiro JS. Delayed effect of Kinesio Taping on neuromuscular performance, balance, and lower limb function in healthy individuals: a randomized controlled trial. Braz J Phys Ther 2016; 20(3): 231-39.

[27] Oliveira AKA, Borges DT, Lins CAA, Cavalcanti RL, Macedo LB, Brasileiro JS. Immediate effects of Kinesio Taping on neuromuscular performance of quadriceps and balance in individuals submitted to anterior cruciate ligament reconstruction: a randomized clinical trial. J Sci Med Sport 2016;19(1):2-6.

[28] Roy SH, De Luca CJ, Casavant DA. Lumbar muscle fatigue and chronic lower back pain. Spine 1989;14:992-1001.

[29] Heydari A, Nargol AV, Jones AP, Humphrey AR, Greenough CG. EMG analysis of lumbar paraspinal muscles as a predictor of the risk of low-back pain. Eur Spine J 2010; 19(7):1145-52.

[30] Added MAN, Costa LOP, Fukuda TY, Freitas DG, Salomão EC, Monteiro RL, et al. Efficacy of adding the Kinesio Taping method to guideline-endorsed conventional physiotherapy in patients with chronic nonspecific low back pain: a randomised controlled trial. BMC Musculoskelet Disord 2013;14:301.

[31] Kolber MJ, Pizzini M, Robinson A, Yanez D, Hanney WJ. The reliability and concurrent validity of measurements used to quantify lumbar spine mobility: an analysis of an Iphone ${ }^{\circledR}$ application and gravity based inclinometry. Int J Sports Phys Ther 2013;8(2):129-37.

[32] Salamh PA, Kolber M. The reliability, minimal detectable change and concurrent validity of a gravity-based bubble inclinometer and iphone application for measuring standing lumbar lordosis. Physiother Theory Pract 2014;30(1):6267. 
501

502

503

504

505

506

507

508

509

510

511

512

513

514

515

516

517

518

519

520

521

522

523

524

525

526

[33] Waddell G, Somerville D, Henderson I, Newton M. Objective clinical evaluation of physical impairment in chronic low back pain. Spine 1992; 17:61728.

[34] Hermens HJ, Freriks B, Disselhorst-Klug C, Rau G. Development of recommendations for SEMG sensors and sensor placement procedures. J Electromyogr Kinesiol 2000; 10(5): 361-74.

[35] Nakagawa TH, Maciel CD, Serrão FV. Trunk biomechanics and its association with hip and knee kinematics in patients with and without patellofemoral pain. Man Ther 2015; 20: 189- 93.

[36] Ostelo RWJG, Deyo RA, Stratford P, Wanddell G, Croft P, Von Korff M. Interpreting Change Scores for Pain and Functional Status in Low Back Pain: towards international consensus regarding minimal important change. Spine 2008; 33(1):90-4.

[37] Sakpal TV. Sample Size Estimation in Clinical Trial. Perspect Clin Res 2010; 1(2): 67-9.

[38] Added MAN, Costa LOP, Freitas DG, Fukuda TY, Monteiro RL, Salomão EC, Medeiros FC, Costa LCM. Kinesio Taping does not provide additional benefits in patients with chronic low back pain who receive exercise and manual therapy: a randomized controlled trial. JOSPT 2016; 46(7):506-13.

[39] Weigl M, Cieza A, Cantista P, Reinhardt JD, Stucki G. Determinants of disability in chronic musculoskeletal health conditions: a literature review. Eur J Phys Rehabil Med 2008;44:67-79.

[40] Osterhues JD. The use of Kinesio Taping in the management of traumatic patella dislocation. A case study. Physiother Theory Pract 2004; 20(4): 267-70.

[41] Jaraczewska E, Long C. Kinesio taping in stroke: improving functional use of the upper extremity in hemiplegia. Top Stroke Rehabi 2006; 13(3):31-42. 

in humans. J Physiol (Lond) 2001;531:289-97.

529 [43] Preece H, White P. Does kinesiology tape increase trunk forward flexion? J 530 Bodyw Mov Ther 2017;21(3): 618-25.

531 [44] Lemos TV, Albino ACG, Matheus JPC, Barbosa AM. The effect of kinesio 532 taping in forward bending of the lumbar spine. J Phys Ther Sci 2014; 26(9):1371533 75.

534 [45] Csapo R, Alegre LM. Effects of Kinesio ${ }^{\circledR}$ taping on skeletal muscle strength 535 A meta-analysis of current evidence. J Sci Med Sport 2015; 18(4): 450-56.

536 [46] Konishi Y. Tactile stimulation with Kinesiology tape alleviates muscle 537 weakness attributable to attenuation of Ia afferents. J Sci Med Sport 2013; 16(1):45538 8. 


\section{Tables}

Table 1. Mean (SD) of age, body mass index (BMI), pain, disability, range of motion for flexion, extension, right lateral flexion, left lateral flexion, RMS of right longuissimus muscle (right RMS - normalized by the peak of the signal), RMS of left longuissimus muscle (left RMS - normalized by the peak of the signal) and strength (normalized by body weight) of the erector spinae muscles for the four groups at the baseline.

\begin{tabular}{|c|c|c|c|c|c|}
\hline Variable & $\begin{array}{c}\text { CG } \\
\mathbf{( n = 2 7 )}\end{array}$ & $\begin{array}{c}\text { KTT } \\
\mathbf{( n = 2 7 )}\end{array}$ & $\begin{array}{c}\text { KTNT } \\
\mathbf{( n = 2 7 )}\end{array}$ & $\begin{array}{c}\text { MP } \\
(\mathbf{n}=\mathbf{2 7})\end{array}$ & $\begin{array}{c}\text { p } \\
\text { value }\end{array}$ \\
\hline Age (years) & $24(4)$ & $25(6)$ & $24(5)$ & $25(5)$ & 0.747 \\
\hline BMI (Kg/m²) & $23.2(2.7)$ & $23.2(3.2)$ & $22.1(3.2)$ & $22.7(2.6)$ & 0.516 \\
\hline Pain (0-10) & $4.9(1.6)$ & $4.9(1.9)$ & $4.9(1.8)$ & $5.1(1.7)$ & 0.977 \\
\hline Disability (0-24) & $8(3)$ & $7(3)$ & $8(4)$ & $7(3)$ & 0.221 \\
\hline Flexion (degree) & $88(19)$ & $92(18)$ & $89(22)$ & $89(16)$ & 0.892 \\
\hline Extension (degree) & $25(8)$ & $24(14)$ & $27(13)$ & $24(12)$ & 0.794 \\
\hline Right Lateral Flexion (degree) & $29(5)$ & $32(7)$ & $30(6)$ & $29(5)$ & 0.113 \\
\hline Left Lateral Flexion (degree) & $28(6)$ & $31(7)$ & $30(5)$ & $28(5)$ & 0.189 \\
\hline Right RMS (\%) & $58.5(6.8)$ & $59.7(7.4)$ & $58.0(5.9)$ & $58.7(6.3)$ & 0.798 \\
\hline Left RMS (\%) & $57.7(7.3)$ & $57.8(6.1)$ & $57.6(5.3)$ & $57.9(6.3)$ & 0.998 \\
\hline Strength (\%) & $196.5(86.7)$ & $212.5(52.5)$ & $196.0(56.3)$ & $191.6(69.3)$ & 0.686 \\
\hline
\end{tabular}

CG: control group; KTT: Kinesio Taping with tension group; KTNT: Kinesio Taping No Tension group; MP: Micropore group; RMS: Root Mean Square. 
Table 2. Mean (SD) for the analysed variables at three time points.

\begin{tabular}{|c|c|c|c|c|c|c|c|c|c|c|c|c|}
\hline \multirow[t]{2}{*}{ Variables } & \multicolumn{3}{|c|}{ CG (n=27) } & \multicolumn{3}{|c|}{$\begin{array}{c}\text { KTT } \\
(\mathrm{n}=27)\end{array}$} & \multicolumn{3}{|c|}{$\begin{array}{l}\text { KTNT } \\
(\mathrm{n}=27)\end{array}$} & \multicolumn{3}{|c|}{$\begin{array}{c}\text { MP } \\
(n=27)\end{array}$} \\
\hline & Pre & 3 days & 10 days & Pre & 3 days & 10 days & Pre & 3 days & 10 days & Pre & 3 days & 10 days \\
\hline Pain (0-10) & $4.9(1.6)$ & $4.4(2.3)$ & $4.6(2.5)$ & $4.9(1.9)$ & $2.5(1.7)$ & $3.4(1.9)$ & $4.9(1.8)$ & $2.5(1.9)$ & $3.2(2.6)$ & $5.1(1.7)$ & $3.8(2.0)$ & $3.4(2.4)$ \\
\hline $\begin{array}{c}\text { Disability } \\
(0-24)\end{array}$ & $8(3)$ & 7 (3) & $7(4)$ & 7 (3) & $4(3)$ & $4(3)$ & $8(4)$ & $5(5)$ & $6(6)$ & $7(3)$ & $5(3)$ & $4(3)$ \\
\hline Flexion (degree) & $88(19)$ & $87(18)$ & $86(15)$ & $92(18)$ & $95(18)$ & $94(19)$ & $89(22)$ & $90(21)$ & $90(22)$ & $89(16)$ & $88(17)$ & $86(16)$ \\
\hline $\begin{array}{c}\text { Right Lateral } \\
\text { Flexion (degree) }\end{array}$ & $29(5)$ & $29(5)$ & $29(7)$ & $32(7)$ & $34(7)$ & $34(7)$ & $30(6)$ & $31(7)$ & $32(6)$ & $29(5)$ & $30(5)$ & $29(5)$ \\
\hline $\begin{array}{l}\text { Left Lateral } \\
\text { Flexion (degree) }\end{array}$ & $28(6)$ & $28(6)$ & $29(6)$ & $31(7)$ & $31(7)$ & $32(7)$ & $30(5)$ & $29(5)$ & $30(5)$ & $28(5)$ & $30(6)$ & $28(5)$ \\
\hline Right RMS (\%) & $58.5(6.8)$ & $62.2(16.0)$ & $59.2(13.2)$ & $59.7(7.4)$ & $67.2(16.0)$ & $65.8(16.5)$ & $58.0(5.9)$ & $62.4(14.1)$ & $63.1(15.2)$ & 58.7 (6.3) & $62.7(13.4)$ & $64.1(17.2)$ \\
\hline Left RMS (\%) & 57.7 (7.3) & $61.5(16.4)$ & $58.5(17.3)$ & $57.8(6.1)$ & $64.1(16.6)$ & $63.8(19.5)$ & $57.6(5.3)$ & $63.1(14.5)$ & $64.1(16.6)$ & $57.9(6.3)$ & $62.9(17.0)$ & 66.5 (22.7) \\
\hline Strength (\%) & 196.5 (86.7) & $212.1(100.5)$ & 216.5 (98.4) & $212.5(52.5)$ & 238.9 (85.1) & $235.2(58.8)$ & $196.0(56.3)$ & $215.9(54.5)$ & $218.2(56.6)$ & $191.6(69.3)$ & 214.9 (63.1) & $212.4(75.2)$ \\
\hline
\end{tabular}

CG: control group; KTT: Kinesio Taping with tension group; KTNT: Kinesio Taping No Tension group; MP: Micropore group; RMS: Root Mean Square. 
Table 3. Mean differences between groups (95\% confidence interval) and p value at pre, 3 days and 10 days after intervention for pain and disability variables.

\begin{tabular}{|c|c|c|c|c|c|}
\hline \multirow[t]{2}{*}{ Time } & \multirow[b]{2}{*}{ Groups } & \multicolumn{2}{|l|}{ Pain } & \multicolumn{2}{|l|}{ Disability } \\
\hline & & $\begin{array}{c}\text { Mean difference } \\
(95 \% \mathrm{CI})\end{array}$ & p value & $\begin{array}{c}\text { Mean difference } \\
(95 \% \mathrm{CI})\end{array}$ & p value \\
\hline \multirow[t]{6}{*}{ Pre } & CG x KTT & $0.037(-1.244$ to 1.318$)$ & 1.000 & $0,852(-1.570$ to 3.274$)$ & 1.000 \\
\hline & CG x KTNT & $0.037(-1.244$ to 1.318$)$ & 1.000 & $-0,407(-2.829$ to 2.015$)$ & 1.000 \\
\hline & CG x MP & $-0.148(-1.429$ to 1.133$)$ & 1.000 & $1.296(-1.126$ to 3.718$)$ & 0.918 \\
\hline & KTT x KTNT & $0(-1.281$ to 1.281$)$ & 1.000 & $1.259(-1.163$ to 3.681$)$ & 0.99 \\
\hline & KTT x MP & $-0.185(-1.466$ to 1.096$)$ & 1.000 & 0.444 (-1.978 to 2.866$)$ & 1.000 \\
\hline & KTNT x MP & $-0.185(-1.466$ to 1.096$)$ & 1.000 & $1.704(-0.718$ to 4.126$)$ & 0.368 \\
\hline \multirow[t]{6}{*}{3 days } & CG x KTT & $1.963 *(0.501$ to 3.425$)$ & 0.003 & $3.481 *(0.825$ to 6.138$)$ & 0.004 \\
\hline & CG x KTNT & $1.926 *(0.464$ to 3.388$)$ & 0.004 & $1.963(-0.693$ to 4.619$)$ & 0.297 \\
\hline & CG x MP & $0.611(-0.851$ to 2.073$)$ & 1.000 & $2.593(-0.064$ to 5.249$)$ & 0.06 \\
\hline & KTT x KTNT & $0.037(-1.425$ to 1.499$)$ & 1.000 & $1.519(-1.138$ to 4.175$)$ & 0.763 \\
\hline & KTT x MP & $-1.352(-2.814$ to 0.11$)$ & 0.087 & $-0.889(-3.545$ to 1.768$)$ & 1.000 \\
\hline & KTNT x MP & $-1.315(-2.776$ to 0.147$)$ & 0.104 & $0.63(-2.027$ to 3.286$)$ & 1.000 \\
\hline \multirow[t]{6}{*}{10 days } & CG x KTT & $1.111(-0.624$ to 2.846$)$ & 0.527 & $3.185 *(0.395$ to 5.975$)$ & 0.016 \\
\hline & CG x KTNT & $1.333(-0.401$ to 3.068$)$ & 0.247 & 0.519 (-2.272 to 3.309) & 1.000 \\
\hline & CG x MP & $1.137(-0.598$ to 2.872$)$ & 0.485 & $2.556(-0.235$ to 5.346$)$ & 0.092 \\
\hline & KTT x KTNT & $-0.222(-1.957$ to 1.512$)$ & 1.000 & $2.667(-0.124$ to 5.457$)$ & 0.069 \\
\hline & KTT x MP & $0.026(-1.709$ to 1.761$)$ & 1.000 & $-0.63(-3.42$ to 2.161$)$ & 1.000 \\
\hline & KTNT x MP & $-0.196(-1.931$ to 1.538$)$ & 1.000 & $2.037(-0.753$ to 4.827$)$ & 0.314 \\
\hline
\end{tabular}

CG: control group; KTT: Kinesio Taping with tension group; KTNT: Kinesio Taping No Tension group; MP: Micropore group. *Significant difference: $\mathrm{p}<0.05$ 


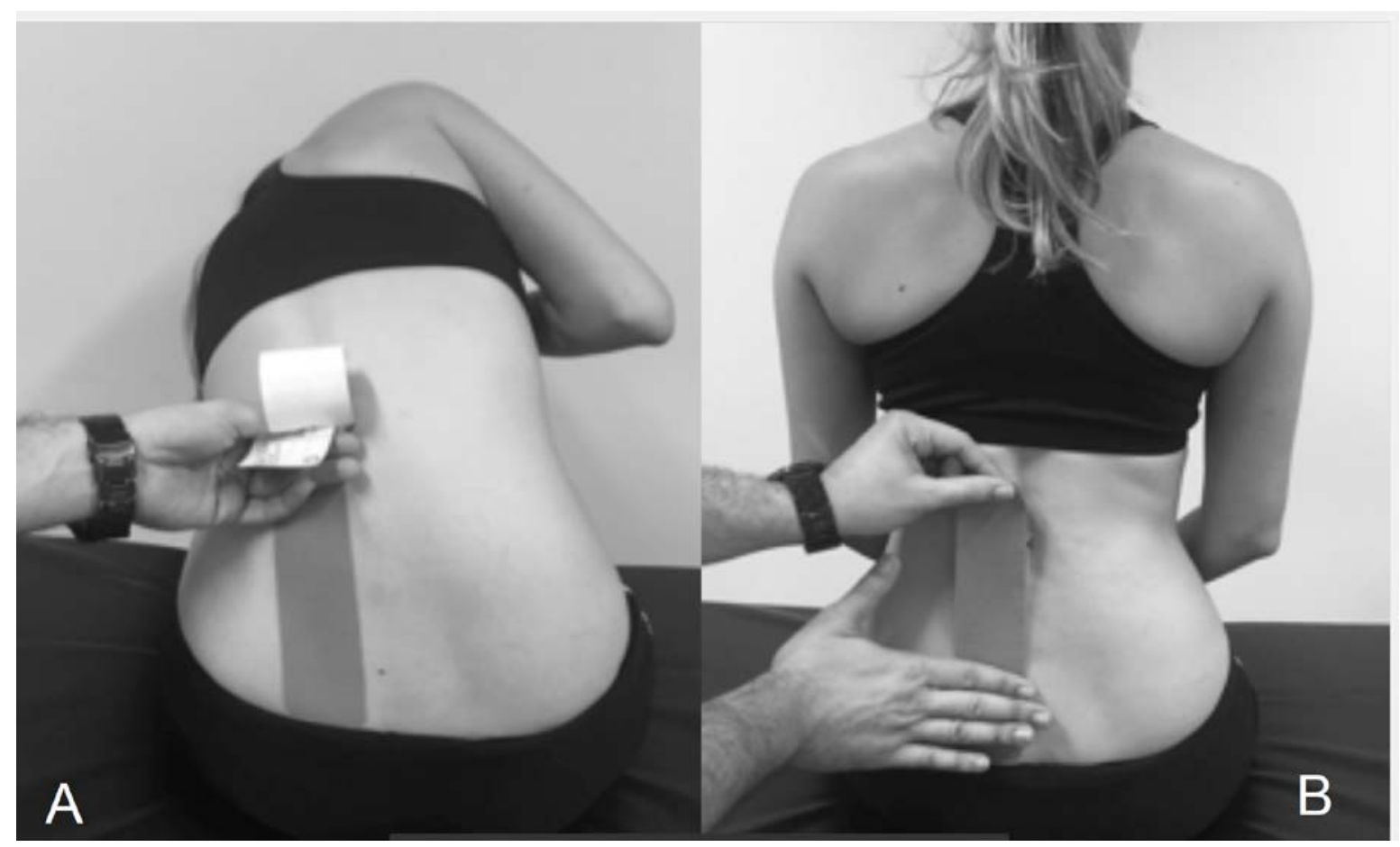

Figure 1. Application of the tape with tension (A) and without tension (B) in the region of erector spinae muscles. 


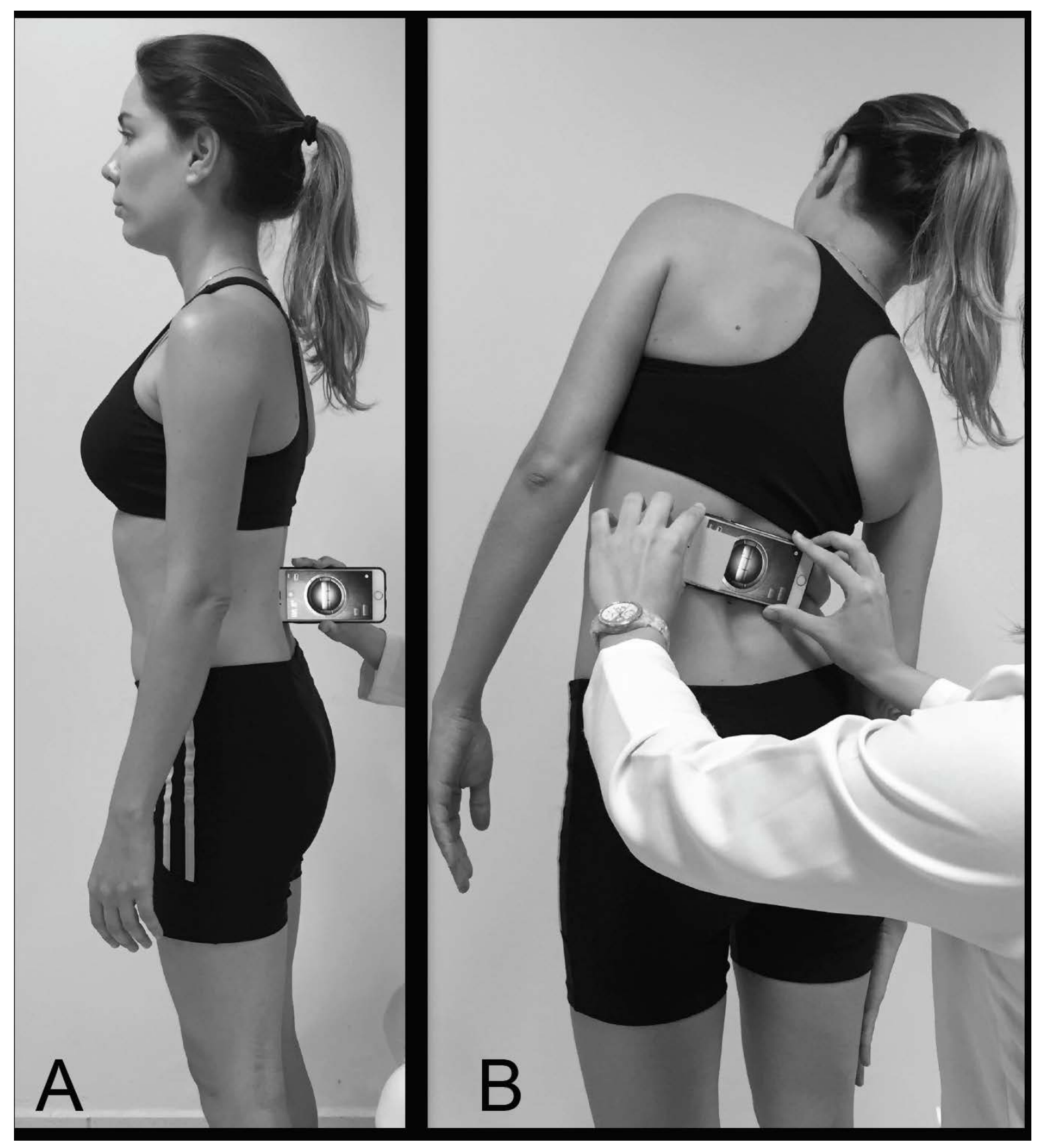

Figure 2. Position of the device to measure flexion and extension (A) and lateral flexion

(B) of the spine. 


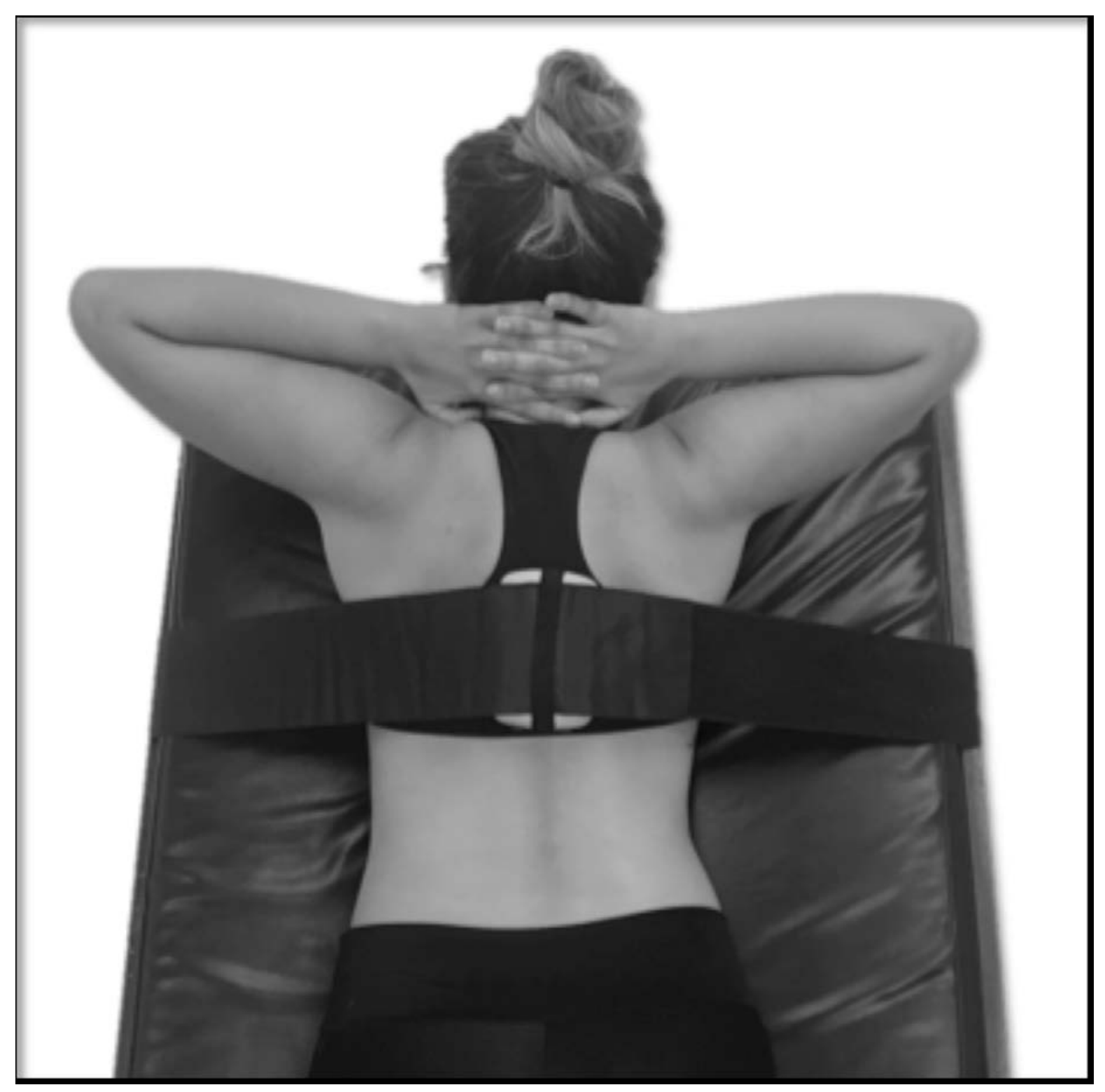

Figure 3. Position of the dynamometer to evaluate trunk extensor strength. 


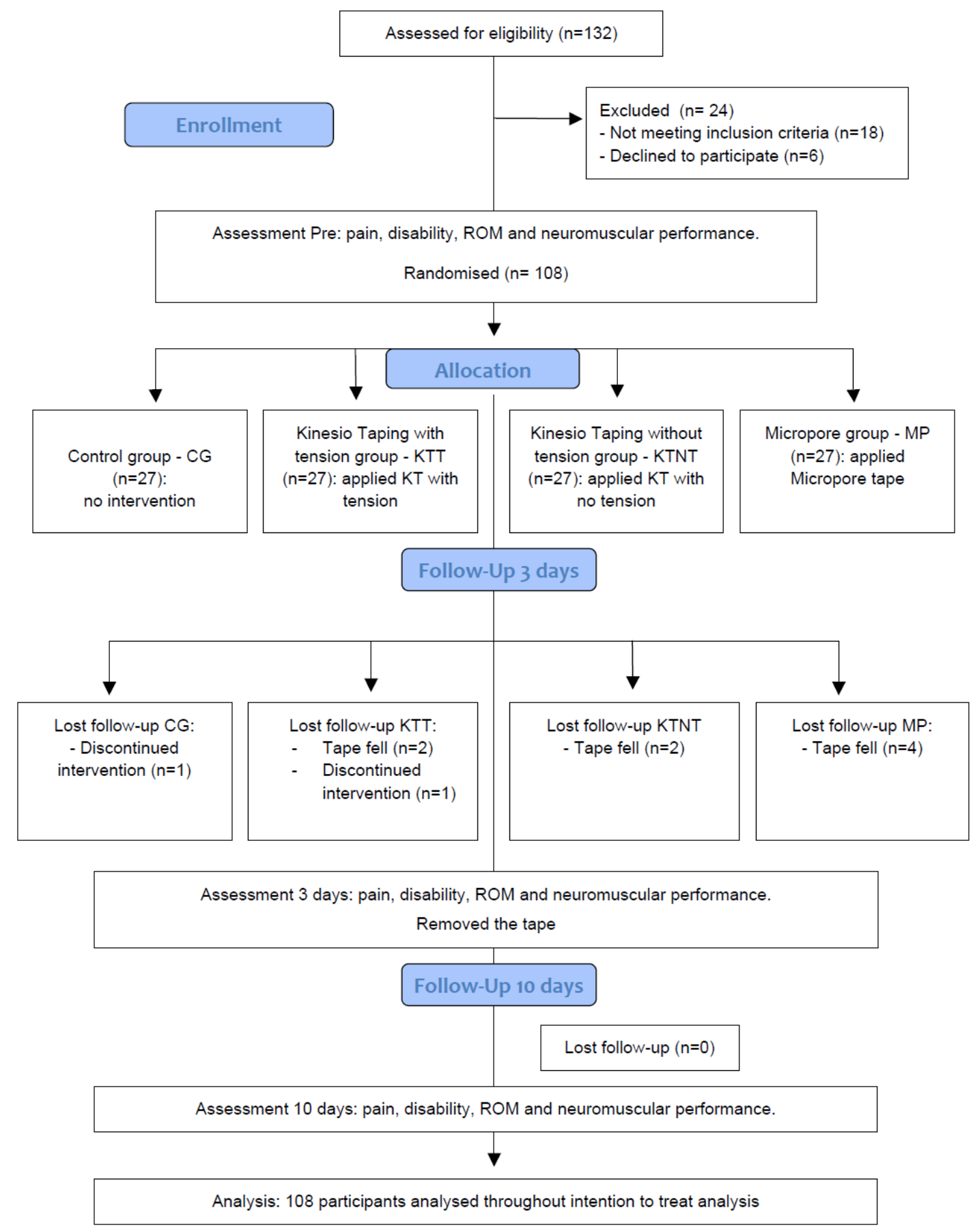

Figure 4. Study flow diagram. 